\section{Successful management of mummified fetus in a heifer by prostaglandin therapy and episiotomy}

\section{Gopal Krishan}

Directorate of Animal Husbandry, Shimla, India

\begin{abstract}
Fetal mummification is one of the gestational accidents that occur due to intra-uterine death of fetus commonly at fourth, fifth and six months of gestation. This report describes the successful management of the mummified fetus in a five year old graded Holstein Friesian heifer cow using single dose of prostaglandin $\mathrm{F} 2 \alpha$ analogue and by performing episiotomy. Antibiotic therapy was given to avoid any uterine infection.
\end{abstract}

\section{Introduction}

Bovine fetal mummification results due to death of conceptus in the uterus between third to eighth months of gestation, without accompanying lysis of corpus luteum and opening of cervix, and is characterized by failure in expulsion of dead fetus, absorption of all fetal fluids, involution of fetal cotyledons and maternal caruncles, and presence of hard, firm fetus in the uterine horn as compact mass with no clinical signs. Persistent corpus luteum helps to maintain the dead fetus within uterus by secreting progesterone. ${ }^{1}$ Fetal mummification has been reported to occur in many domestic species but this reproductive disorder affects the economy of dairy farms by increasing inter calving period as well as fetal loss. ${ }^{1}$ The incidence of fetal mummification in cattle is sporadic and found to be $0.13-1.8 \% .2,3$ The present study describes the successful management of the mummified fetus in a heifer cow using single dose of prostaglandin F2 $\alpha$ (PGF2 $\alpha$ ) analogue and by performing episiotomy.

\section{Case Report}

A five-year-old graded Holstein Friesian heifer, weighing $450 \mathrm{~kg}$, was presented with the complaint of not showing any signs of parturition even after completion of full term of pregnancy. The owner of the cow told that she had been inseminated 310 days before and pregnancy was confirmed at $60^{\text {th }}$ and $90^{\text {th }}$ day after insemination. Apparently the clinical parameters of heifer including heart rate, pulse rate, temperature, respiratory rate and posture were normal with no visual signs of pregnancy. On vaginal examination, the cervix showed one finger dilatation with no discharge. Per rectal examination revealed no fetal movement and a hard bony mass without the palpation of cotyledons adhering to uterine wall, no fremitus and absence of fetal fluid. Based on clinical signs and observations cow was diagnosed to be having mummified fetus and decided to treat medically.

The animal was given an intramuscular single dose of PGF2 $\alpha$ analogue cloprostenol and dicrysticin was started (for five days) as antibiotic therapy to prevent probable uterine infection. After 72 hours of the therapy, a long thick shred of brownish mucoid discharge from vulva was reported. Per vaginally, the cervix was found fully relaxed and a huge bony mass draped within the fetal membranes was palpated. A mild traction was applied to take out the dead fetus but labial narrowness hindered the easy passage. Episiotomy was performed as it appeared that further traction will result in tearing of vulva. A $3-5 \mathrm{~cm}$ incision using scalpel blade was made on the dorsal commissure after locally anaesthetizing the area with $2 \%$ lignocaine hydrochloride aseptically and fully grown dead fetus covered with dark brown fetal membranes was delivered manually (Figure 1). Following parturition, the incision was cleansed of foreign materials such as fetal remnants and sutured with horizontal mattress suture pattern.

\section{Discussion and Conclusions}

Fetal mummification has been reported in several species but it is more common in cattle. ${ }^{1}$ Several potential causes such as infectious (including bovine viral diarrhea, leptospirosis and molds) ${ }^{1}$ and mechanical (compression or torsion of umbilical cord, ${ }^{4}$ uterine
Correspondence: Gopal Krishan, Directorate of Animal Husbandry, Shimla Rural, 171005, Shimla, Himachal Pradesh, India.

E-mail: vet_krish@rediffmail.com

Key words: Fetal mummification; prostaglandin; episiotomy.

Conflict of interest: the author declares no potential conflict of interest.

Received for publication: 25 January 2015. Accepted for publication: 25 February 2015.

This work is licensed under a Creative Commons Attribution NonCommercial 3.0 License (CC BYNC 3.0).

(C) Copyright G. Krishan, 2015

Licensee PAGEPress srl, Italy

Veterinary Science Development 2015; 5:5829

doi:10.4081/vsd.2015.5829

torsion, ${ }^{5}$ defective placentation, ${ }^{6}$ and genetic abnormalities) ${ }^{7}$ have been observed for causing this condition. Mummification of fetus in cattle usually occurs between 3-8 months of gestation and thereafter, the dead fetus is retained after absorption of all fetal and placental fluids into the uterus because of persistent corpus luteum. Further the fetal membranes adhere to the dead fetus and form the viscous brown material over dehydrated fetus. Apparently a hard bony mass with closed cervix but without placentomes, fremitis and fetal fluid remains in the uterus which was experienced per rectally in the present case. Similar finding on rectal examination were reported by Azizunnesa et al. ${ }^{8}$

The physical examination of the dam reveals no abnormality, except for some rare cases in which reduced milk production and gradual weight loss has been recorded. ${ }^{9}$ The medical treatment involves the lysis of corpus luteum by PGF2 $\alpha$ injection which results in the expulsion of mummified fetus within 2 to 4 days. ${ }^{3}$ Arthur et al. ${ }^{10}$ reported that the treat- 
ment of mummified fetus with PGF2 $\alpha$ created some complexity in cattle viz. maceration of mummified fetus and packed in the birth canal instead of expelled out. However, no such complication was experienced in the present study. Dabas and Chaudhari also delivered mummified fetus easily by mild traction after 72 hour of the prostaglandin therapy.11

\section{References}

1. Roberts SJ, ed. Veterinary obstetrics and genital diseases. 2nd ed. New Delhi: CBS Publishers and Distributors; 2012. pp 213233.

2. Roberts SJ, ed. In: Veterinary obstetrics and genital diseases: theriogenology. 2nd ed. New Delhi: CBS Publishers and Distributors; 1971. pp 170-174.

3. Barth AD. Induced abortion in cattle. In: Morrow DA, ed. Current therapy in Theriogenology. 2nd ed. Philadelphia: W.B. Saunders; 1986. pp 205-208.

4. Mahajan M, Sharma A. Haematic mummification due to umbilical cord torsion in a cow: a case report. Ind Vet J 2002;79:118687.

5. Moore AA, Richardson GF. Uterine torsion and fetal mummification in a cow. Can Vet J 1995;36:705-6.

6. Irons PC. Hysterotomy by a colpotomy approach for treatment of foetal mummification in a cow. J S Afr Vet Assoc 1999;70:127-9.
7. Stevens RW, King GJ. Genetic evidence for a lethal mutation in Holstein-Friesian cattle. J Hered 1968;59:366-8.

8. Azizunnesa M, Sutradhar BC, Das BC, et al. A case study on mummified foetus in a heifer. Univ J Zool Rajshahi Univ 2010;28:61-3.

9. Frazer GS. Obstetrics part 1. Pregnancy complications in the cows. Proc North Am Vet Conf 2004:9-12.

10. Arthur GH, Noakes DE, Person H, Parkinson TJ. Sequelae to embryonic or foetal death. In: Veterinary reproduction and obstetrics. 7th ed. Philadelphia: W.B. Saunders; 1996. pp 127-128.

11. Dabas VS, Chaudhari CF. Management of mummified fetus in a cow. Int $\mathbf{J}$ Agro Vet Med Sci 2011;5:365-7. 